\title{
(iv)
}

\section{Market Access and wages: A spatially heterogeneous approach}

Dusan Paredes

Victor Iturra

Serie de Documentos de Trabajo en Economía - UCN

https://sites.google.com/a/ucn.cl/wpeconomia

Identificador: WP2012-15

Antofagasta - Septiembre 2012

www.ucn.cl

Avda. Angamos 0610, Pab. X10, Antofagasta, Chile

Tel: + 5655355746 - Fax: + 5655355883 


\title{
Market Access and wages: A spatially heterogeneous approach*
}

\author{
Dusan Paredes, Victor Iturra ${ }^{1}$
}

Universidad Católica del Norte, Faculty of Economics, Antofagasta, Chile.

\begin{abstract}
:
We empirically test the positive relationship between market access and wages stated by New Economic Geography. Contrary to most estimation in other countries, we find evidence of significant spatial heterogeneity of this elasticity across Chilean communities.
\end{abstract}

JEL classification: J3, R1

Keywords: New Economic Geography, wages, market access, Geographically Weighted regression

\section{Resumen:}

Empíricamente estimamos la relación positiva entre acceso al mercado y salarios señalada por la Nueva Geografía Económica. Contrario a la mayoría de las estimaciones de otros países, encontramos evidencia de una significativa heterogeneidad espacial de esta elasticidad a través de las comunas chilenas.

Clasificación JEL: J3, R1

Palabras clave: Nueva Geografía Económica, salarios, acceso al mercado, regresión geográficamente ponderada.

\footnotetext{
* The authors acknowledge and appreciate the comments of a referee and the support of the Project NS 100046 of the Iniciativa Científica Milenio of the Ministerio de Economía, Fomento y Turismo, Chile and the Chilean Fondecyt No. 1111061 'Evaluación Económica de la Política Regional en Chile'

${ }^{1}$ Corresponding author: Deparment of Economics, Universidad Catolica del Norte, Avenida Angamos 0610, Antofagasta, Chile. Tel.: 5655 355794; fax: 5655 355883. E-mail addresses: dparedes @ucn.cl (D. Paredes), viturra@ucn.cl (V. Iturra).
} 


\section{Introduction}

From the seminal contribution of Krugman (1991), the literature tests the empirical relationship between market access (MA) and wages. As the New Economic Geography (NEG) states, firms prefer locations close to large markets because they save transport costs and gain benefits from increasing returns to scale. The firms reward their production factors with higher wages, but they also face congestion costs, such as high land rents (Niebuhr, 2006). In many developed countries, the MA-wage elasticity is positive and significant (Brakman et. al. 2004, 2009, Garcia 2006, Mion 2004, Niebuhr 2006). This paper examines this hypothesis in a developing country with a high dependence on natural resources: Chile. In Chile, natural resource endowments are clustered in the far north and far south of the country (copper in the north and salmon in the south), far away from the main MA, the Metropolitan Region (MR) of Santiago (see Figure 1). Given the benefits derived from the high prices of copper during the last years of the twentieth century (Lagos and Blanco, 2010) and the entry of the salmon industry into foreign markets, the most northern and southern areas of Chile have high wages even when they do not enjoy substantial MA. This scenario creates a situation that is ignored by NEG: higher wages cannot be positively correlated with greater MA. This implies that absolute advantages and low urban density generate higher wages such as metropolitan areas. Remote areas with advantages from initial endowments can also benefit from the favorable cycle of natural resource prices. Although Krugman admits that natural resources endowments matter, NEG models did not incorporate their potential effect on agglomeration economies, Kilkenny (1998a) piece brings that detail more to the front, highlighting the importance how natural resources that influence rural development are distributed ${ }^{2}$.

We test our hypothesis by estimating the relationship between wages and MA for Chilean communities (the smallest administrative region) but still allow for varying MA-wage elasticity across space. This strategy allows us to evaluate whether this elasticity is more important in the MR than in the extreme northern and southern regions of the country. To assure a robust proxy for regional wages, we must isolate the effect of human capital on wages. Spatial sorting of skills (Combes et al. 2008) or urban productivity (Glaeser et. al. 2001) affects the wage differentials even with similar MA. Consequently, this paper controls for human capital by using two techniques. The first technique runs a regression à la Mincer, and fixed effects are estimated for each community, while the second technique uses a multilevel regression to generate a random wage effect attributable to each community while also controlling for human capital. We also use the communal average wage as a third measurement of wage differences to show its high instability for our empirical strategy. These three measurements are used as proxies for aggregated wages in a second stage where the MA-wage elasticity is estimated. The spatial variation is obtained using a geographically weighted regression.

Chile does not follow the theoretical positive relationship suggested by NEG across the entire country. In fact, when we consider the MA-wage elasticity alone, it is possible to find three types

\footnotetext{
${ }^{2}$ The authors acknowledge the wise comments of anonymous referee to reword this phrase.
} 
of spatial units. First, a set of communities, especially those located near the MR, show a positive but low elasticity. For a second set of communities, any specification of aggregated wages is not significant. Finally, the third set of spatial units shows a negative relationship between MA and wages. These results support our hypothesis that MA, grounded on NEG, is not sufficient to understand spatial wage variations. We also consider the negative externalities associated with large concentrations-primarily the role played by housing prices (Paredes (2011), Paredes and Iturra, (2012)). We expect negative externalities to diminish the elasticity between MA and wages. Our results confirm our expectation, and the MA-wage elasticity is even lower than the previous result. Moreover, large sets of communities do not follow the theoretical condition of positive elasticity. Consequently, we conclude that NEG is not sufficient for understanding the wage distribution of countries with high natural resource dependency. In these cases, the increasing returns derived from absolute advantages also play a role in explaining regional inequalities in wages. This exercise suggests new branches for theoretical research in the NEG discipline and a new avenue of discussion for applied economists, especially for countries where there are multiple sources of wage inequality.

\section{Methodology}

Geographically weighted regression (GWR), proposed by Fotheringham, Brunsdon and Chartlon (2002), is a methodology that allows spatial variability on estimated parameters across space. In other words, GWR does not assume that relationships in the model are constant over space (a non-stationary process). As Deller (2011) noted, GRW has been widely used to analyze spatial phenomena such as the hedonic modeling of housing prices, rural poverty patterns, migration patterns and the role of entrepreneurship in economic growth. In this research, a GWR model will be used to analyze the spatial variation of the relationship between MA and wage differences across Chilean communities. Formally:

$$
y_{i}=\beta_{0}\left(u_{i}, v_{i}\right)+\sum_{k} \beta_{k}\left(u_{i}, v_{i}\right) x_{i k}+\varepsilon_{i}
$$

where $k$ is the number of exogenous parameters, $\left(u_{i}, v_{i}\right)$ denotes the coordinates of the $i t h$ point in space and $\beta_{k}\left(u_{i}, v_{i}\right)$ is a realization of the continuous function $\beta_{k}(u, v)$ at point $i$. The dependent variable $y_{i}$ is a $N x 1$ vector of one of our three measures of aggregate wages, and $x_{i k}$ represents a $N x k$ matrix with different independent variables, namely, MA and housing price averages. According to NEG, we should find a positive relationship between $y_{i}$ and $M A$; in other words, wages should be higher in places with greater MA. The parameters for each point $i$ th are estimated by:

$$
\hat{\beta}(i)=\left(X^{\prime} W_{i} X\right)^{-1} X^{\prime} W_{i} Y,
$$

where $W_{i}$ is an $n x n$ spatial diagonal weighting matrix, with zero for all others elements. Data from observation close to $i$ are weighted more heavily than data from observations further away. The spatial weighting function $s_{i j}$ is defined as: 


$$
s_{i j}=\exp \left[-\left(\frac{d_{i j}}{b}\right)^{2}\right]
$$

where $d_{i j}$ is the distance (Kms.) between communities $i$ and $j$, and $\mathrm{b}$ is the spatial bandwidth. If $i=j$, then the weighting of data at that point will be unity, and the weighting scheme of other data will decrease according to the Gaussian curve as the distance between $i$ and $j$ increases.

\section{Data}

The data were obtained from the 2009 National Socioeconomic Characterization Survey (CASEN) with statistical representation from 334 Chilean communities. First, the communal wage differences were estimated using three approaches: 1) regression à la Mincer where the fixed effects are interpreted as communal wages, 2 ) a multilevel model where the random effect is the proxy for communal wages and 3) communal average wage. The first and second approaches control for worker characteristics such as years of education, years of experience, sex and economic sectors dummies ${ }^{3}$. To represent congestion costs, we use the average housing rent for each community. The NEG suggest that MA increases nominal wages but that price levels also have an effect. High concentrations create an increase in housing prices, lowering real wages. Moreover, according to Roback (1982), urban density is capitalized by housing prices, and a proper control is needed. In this scenario, housing prices must be considered in the econometric specification of NEG. In the second step, communal wages are used to build the wage equation sustained by NEG:

$$
w_{i}=\beta_{0 i}\left(u_{i}, v_{i}\right)+\beta_{1 i}\left(u_{i}, v_{i}\right) M A_{i}+\beta_{2 i}\left(u_{i}, v_{i}\right) H P_{i}+\varepsilon_{i},
$$

where $w_{i}$ is wages, $M A_{i}$ is Market Access and $H P_{i}$ is the average rent for housing. All of these variables are measured for each spatial unit $i$. The spatial distribution of these variables is shown on Figure 1. Thus, the wage equation (4) requires two inputs: MA and HP. The MA is estimated as a weighted average of population as a proxy of MA:

$$
M A_{i}=\sum_{j} \frac{\mathrm{P}_{j}}{d_{i j}}
$$

where $P_{j}$ is the population of $j$ th commune and $d_{i j}$ is the centroid distance between commune $i$ and $j$. For $d_{i i}$, a common convention is used in $d_{i i}=(2 / 3) \sqrt{A_{i} / \pi}$ where $A_{i}$ is the region's area in square kilometers (Head and Mayer, 2003). To provide a descriptive idea of the Chilean case, Figure 1 shows the spatial distribution of communal wages (for both specifications), communal average wages, MA and HP. As can be seen, we found a similar spatial pattern using the three measures of communal wage differences: the highest wages are located in the middle (MR) and extremely northern and southern communities in the country. In contrast, MA follows a rather different pattern; that is, the highest values of the country are located in the middle of the country whereas the lowest values are located in the extreme north and south. HP spatial distribution is

\footnotetext{
${ }^{3}$ The data set and Stata ${ }^{\circledR}$ code are available from the authors upon request.
} 
similar to wage difference patterns - the highest values are concentrated in the far north and south and in the middle of the country.

Figure 1: Spatial distribution of the wage differences, MA, and HP.

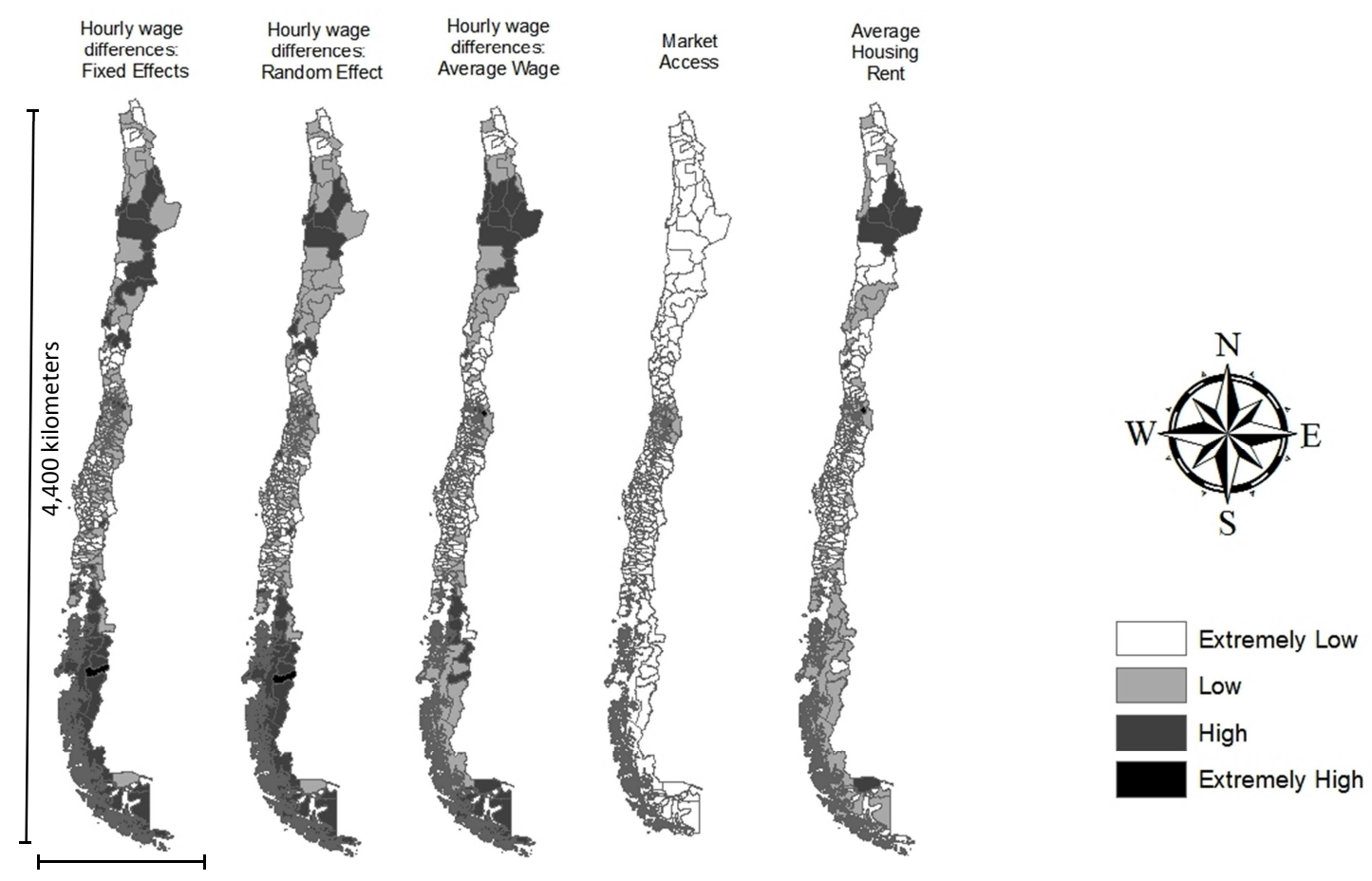

Average: 180 kilometers

Source: Authors

\section{Results}

Our results are reported in Table 1. We show the robustness of our results with the use of three dependent variables. We expect that Fixed Effects (FE) and Random Effects (RE) (namely, the first and second rows) show a better behavior than the wage average because of the spatial sorting of skills. Simultaneously, we set the spatial neighborhood for three different rings or bandwidths: 100, 300 and 500 kilometers. We follow this strategy to avoid the problem known as Modifiable Areal Unit Problem (MAUP). By using these bandwidths, the data will indicate the correct geographic scale, where the MA-wage elasticity is revealed. Finally, we test the NEG model by including negative externalities of dense areas captured through housing price. 
We split the estimation into two approaches. The first approach only considers the spatial interaction between wages and MA (namely, the market access column in table 1). For this approach, the results show that the minimum elasticity is below zero when any ring is considered. For example, when the spatial neighborhood is considered up to 100 kilometers, we find a minimum elasticity of -0.463 when FE is used as a dependent variable. This result implies that Chile presents some spatial units with high/low wages, but where the MA is low/high, this result indicates the opposite relationship compared with the NEG statements. This unusual relationship is stable for wider rings, namely, 300 and 500 kilometers, where the number of spatial units with negative elasticities are between $19 \%$ and $5 \%$ of the total sample. The maximum elasticity is extremely high for the smallest ring, which indicates that spillover effects are locally clustered. When the neighborhood is extended beyond 100 kilometers, the spatial interaction between wages and MA is reduced. The average shows a representative case for the whole country, and the elasticity is extremely low-about $3 \%$. This magnitude is low compared with other countries, where the wage-MA elasticity is about $20 \%-30 \%$. The significant and positive magnitudes are only identified around the MR, but the elasticity is low for rings larger than 100 kilometers.

Previous results are consistent when the RE is considered. Again, some spatial units show negative elasticity. To assess whether the NEG could explain the spatial units with higher density, namely, the communities in the MR, we provide the range of elasticities for those communities. We see that the range is low, and only the smallest ring presents MA-wage elasticity slightly over $20 \%$, whereas this measurement is well below $20 \%$ for the other estimates. The fraction of communities with negative elasticity is between $6 \%$ and $22 \%$ of the total sample size. The range of elasticity for alternative rings is consistent with the FE estimation, and the complete set of estimations supports our hypothesis that the NEG does not properly explain the case of Chile and how the NEG performance is weakened by absolute advantages. Again, the elasticity range is low for the whole country, and its magnitude is low even for the MR. Finally, the average wage estimates confirm our hypothesis about the poor quality of this variable since the results are distorted by not controlling for human capital. Therefore, unexpected elasticities appear. The maximum and minimum levels of the elasticity are outside theoretical expectations, and the average elasticity is clearly overestimated. This result supports our hypothesis about the relevance of considering the spatial sorting of human capital, which can largely explain the wage differentials. In summary, this exercise shows that a consistent proportion of spatial units present negative wage-MA elasticity, with a higher proportion in the low rings of spatial interaction. These results support that spatial spillovers derived from MA are highly clustered in small functional areas. Moreover, the average range is low in Chile compared with other countries.

To properly test the role of the benefits derived from spatial concentration, we also incorporate the role of congestion costs (Helpman, 1998 and Brakman et al., 2004) in the second approach. Our hypothesis establishes that MA-wage elasticity is overestimated when congestion costs are not incorporated, especially for housing prices. These results are presented on the right side of table 1. With respect to the $\mathrm{FE}$, the proportion of negative elasticity is similar to the previous model, but the range of estimations is slightly different. The maximum values are lower than the 
previous estimations, and the average is also lower. The new total elasticity is about 1 percent. A similar conclusion is obtained for RE and average wages. This set of results supports our hypothesis. First, some spatial units do not follow the theoretical implications derived by the NEG. Chile has regions where the wage and MA are not positively correlated, and this measurement is robust across several wage categories. Second, the nature of spillovers generated by MA would seem to be locally clustered, and the spillovers decrease for rings larger than 100 kilometers. Finally, the role of congestion costs is relevant for evaluating the NEG. The incorporation of housing price reduces the majority of the elasticity estimations.

The second set of hypotheses to be compared relates to the geographical distribution of the elasticity. As can be seen in figure 2, there are three groups of communities. First, in the extreme north of the country, there is a group of communities that show low MA and low wages; thus, elasticity is positive and high (red circles on right map). By comparison, in the extreme south of the country, a group of communities show a negative elasticity, which is explained by low MA and high wages (gray circles). Finally, in the middle of the country, an important group of communities that belong to RM show high MA and high wages, and a positive elasticity therefore appears. This result shows how the absolute advantage also generates higher wages, which is evident, for example, in the southern side of the country. Moreover, the NEG seems to be useful for understanding only a portion of the country, especially where large urban agglomerations exist. In this sense, Kilkenny (1998b) provides a theoretical framework to consider how differences such as changes in relative average industrial transport costs can favor rural development. This framework goes further than the NEG, making an effort to explain and understand how spatial configuration deals with economies characterized by a high dependence on natural endowment, such as the Chilean economy. 
Table 1: MA elasticity for different wage specifications and bandwidth distances

\begin{tabular}{|c|c|c|c|c|c|c|c|}
\hline \multirow{4}{*}{$\begin{array}{c}\text { Dependent } \\
\text { variable }\end{array}$} & \multirow{4}{*}{$\begin{array}{l}\text { Market Access } \\
\text { Elasticity } \\
\text { Measurements }\end{array}$} & \multicolumn{6}{|c|}{ Independent variables } \\
\hline & & \multicolumn{3}{|c|}{ Market Access } & \multicolumn{3}{|c|}{ Market Access +Average Rent Price } \\
\hline & & \multicolumn{3}{|c|}{ Bandwidth Distance (Kms.) } & \multicolumn{3}{|c|}{ Bandwidth Distance (Kms.) } \\
\hline & & 100 & 300 & 500 & 100 & 300 & 500 \\
\hline \multirow{5}{*}{$\begin{array}{l}\text { Fixed } \\
\text { Effects }\end{array}$} & Min & -0.463 & -0.233 & -0.081 & -0.413 & -0.141 & -0.089 \\
\hline & Max & 0.679 & 0.116 & 0.036 & 0.27 & 0.089 & 0.019 \\
\hline & Average & 0.022 & 0.028 & 0.027 & 0.007 & 0.012 & 0.011 \\
\hline & $\%$ negative & $19 \%$ & $11 \%$ & $5 \%$ & $39 \%$ & $9 \%$ & $5 \%$ \\
\hline & R.M. range & {$[0.006-0.21]$} & {$[0.007-0.058]$} & {$[0.029-0.036]$} & {$[-0.099-0.017]$} & $\mid[-0.086-0.012]$ & {$[0.007-0.014]$} \\
\hline \multirow{5}{*}{$\begin{array}{l}\text { Random } \\
\text { Effects }\end{array}$} & Min & -0.543 & -0.243 & -0.099 & -0.523 & -0.162 & -0.109 \\
\hline & Max & 0.538 & 0.149 & 0.039 & 0.232 & 0.123 & 0.019 \\
\hline & Average & 0.023 & 0.03 & 0.028 & 0.001 & 0.009 & 0.008 \\
\hline & $\%$ negative & $22 \%$ & $13 \%$ & $6 \%$ & $55 \%$ & $12 \%$ & $7 \%$ \\
\hline & R.M range & {$[0.003-0.141]$} & {$[0.005-0.076]$} & {$[0.031-0.039]$} & {$[-0.364-0.006]$} & $\mid[-0.102-0.009]$ & {$[0.005-0.013]$} \\
\hline \multirow{5}{*}{$\begin{array}{l}\text { Average } \\
\text { Wages }\end{array}$} & Min & -2.142 & -1.784 & -0.546 & -3.636 & -2.376 & -0.548 \\
\hline & Max & 1.989 & 1.2 & 0.241 & 1.629 & 0.821 & 0.096 \\
\hline & Average & 0.198 & 0.177 & 0.155 & 0.021 & 0.028 & 0.033 \\
\hline & $\%$ negative & $16 \%$ & $12 \%$ & $4 \%$ & $45 \%$ & $9 \%$ & $6 \%$ \\
\hline & R.M range & {$[0.031-0.614]$} & {$[0.055-0.472]$} & {$[0.161-0.241]$} & {$[-2.925-0.069]$} & {$[-1.077-0.035]$} & {$[0.004-0.046]$} \\
\hline
\end{tabular}

Source: Authors 
Figure 2: Spatial distribution of MA, wage fixed effects and MA-wage elasticity

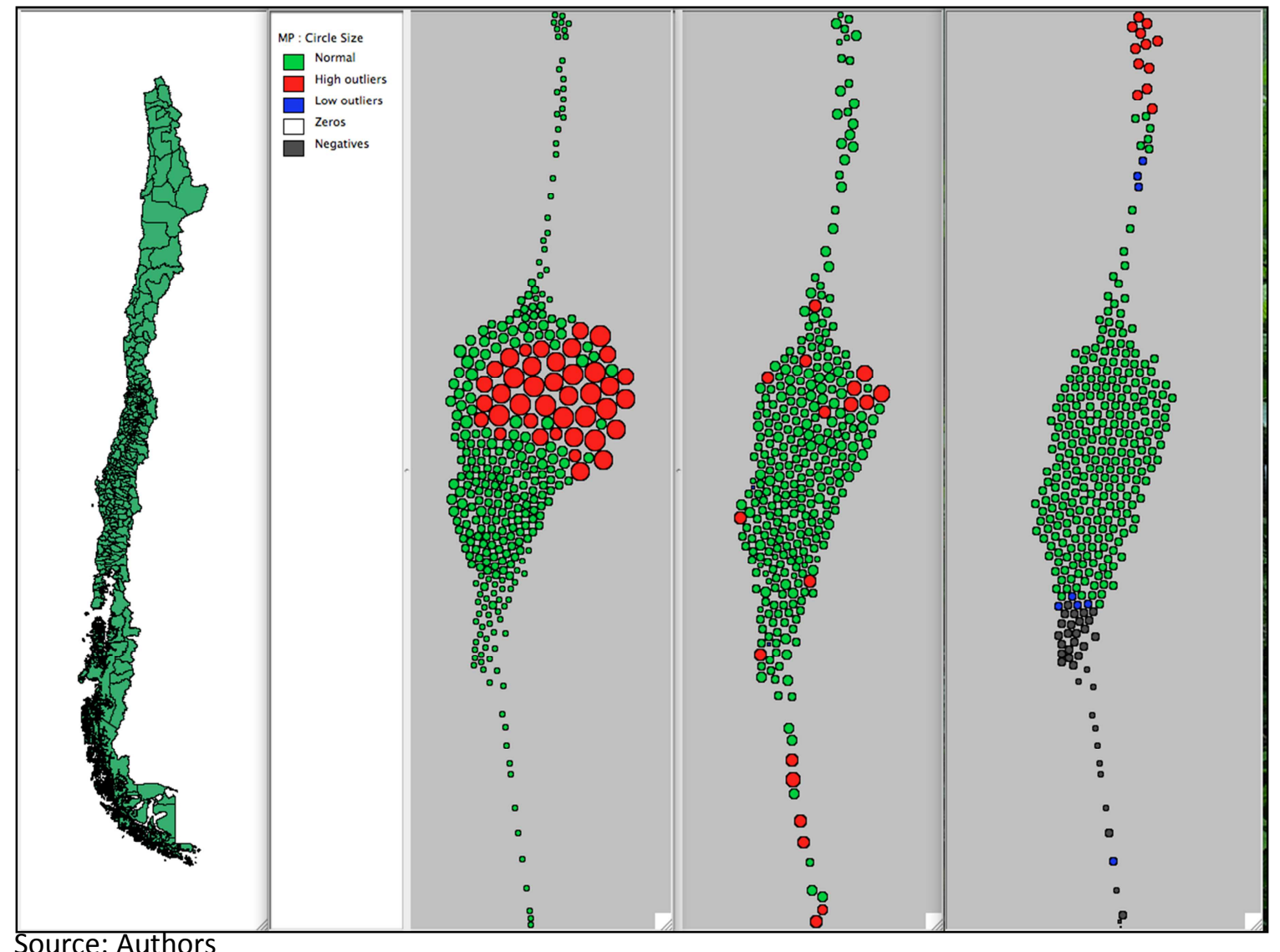

5. Conclusion

We test the explicative power of the NEG framework in a country where the MA does not coincide with the natural resource endowment high dependency of natural resource production. While the NEG has been widely tested in the literature, we do not have sufficient evidence about its explicative power for developing countries. We show how heterogeneous this measurement is across space, reflecting that some spatial units more frequently present negative elasticity. We show the robustness of our estimations by using different dependent variables by controlling for additional factors, such as housing price. The main result of this research shows that there is a clear MA-wage elasticity heterogeneity throughout Chilean communities. The geographical scope of the positive externalities derived from spatial agglomeration does not seem to exceed 100 kilometers. Inside these rings, there are communities with positive and negative elasticity, which provides evidence regarding the need to go further with the NEG framework to understand the spatial distribution of wages when the spatial units also present absolute advantages. Moreover, the theoretical models of NEG should move toward the representation of these types of stylized facts in the future. 


\section{References}

Brakman S., Garretsen H., \& Schramm M., (2004). The spatial distribution of wages: Estimating the Helpman-Hanson Model for Germany. Journal of Regional Science. 44, №3, 437-466.

Combes, P., Duranton, G., \& Gobillon, L., (2008). Spatial wage disparities: Sorting mattersi. Journal of Urban Economics. 63.723-742.

Deller, S., Spatial heterogeneity in the wage curve. Economics Letters (2011), doi:10.1016/j.econlet.2011.04.015

Fotheringham, S., C. Brunsdon and M. Charlton. (2002). Geographically Weighted Regression: The Analysis of Spatially Varying Relationships. Chichester: Wiley.

Garcia, A., (2006). Estimating Krugman's economic geography model for the Spanish regions. Spanish Economic Review. 8:83-112.

Glaeser, E., Kolko, J., \& Saiz, A., (2001).Consumer city. Journal of Economic Geography.1, 27-50.

Head, K. \& and Mayer, T. (2003). The empirics of agglomeration and trade, Discussion Paper $\mathrm{N}^{\circ} 3985$. Centre for Economic Policy and Research, London.

Helpman, E., (1998). The size of regions. In: Pines D, Sadka E, Zilcha I (eds) Topics in public economics, Cambridge University Press, pp 33-54

Krugman, P., (1991). Increasing returns and economic geography. Journal of Political Economy, 3, 483-499.

Lagos, G., \& Blanco E., (2010). Mining and development in the region of Antofagasta. Resource Policy. 35. 265-275.

Kilkenny, M., (1998a). Transport costs, the New Economic Geography and rural development. Growth and Change. Vol.29, pp. 259-280.

Kilkenny, M., (1998b). Transport costs and rural development. Journal of Regional Science. Vol 38, $\mathrm{N}^{\circ} 2$, 1998, pp.293-312.Mion, G 2004, Spatial Externalities and empirical analysis: the case of Italy. Journal of Urban Economics. 56, 97-118.

Niebuhr, A., (2006). Market Access and regional disparities. New economic geography in Europe. Annals of Regional Science. 40:313-334.

Paredes, D., (2011) A methodology to compute regional housing price index using matching estimator methods. Annals of Regional Science, Vol. 46, Number 1: 139-157

Paredes, D., \& Iturra,. V., (2012) Substitution bias and the construction of a spatial cost of living index. Papers in Regional Science doi:10.1111/j.1435-5957.2011.00408.x 
Roback, J., (1982). Wages, Rents, and the Quality of Life. The Journal of Political Economy. $90 . \mathrm{N}^{\circ} 6$. 1257-1278. 